\title{
Role of the JAK/STAT signaling pathway in the pathogenesis of acute myocardial infarction in rats and its effect on NF- $\mathrm{NB}$ expression
}

\author{
SONG ZHANG ${ }^{1}$, XIN LIU $^{1}$, STEVEN GOLDSTEIN $^{2}$, YIGANG LI $^{1}$, JUNBO GE $^{3}$, \\ BEN HE ${ }^{4}$, XUETAO FEI ${ }^{1}$, ZUYUE WANG $^{2}$ and GEORGE RUIZ ${ }^{2}$
}

\begin{abstract}
${ }^{1}$ Department of Cardiovascular Diseases, Xinhua Hospital, Shanghai Jiaotong University, School of Medicine, Shanghai 200092, P.R. China; ${ }^{2}$ Department of Cardiology, Washington Hospital Center, Washington, DC 20010, USA; ${ }^{3}$ Department of Cardiovascular Diseases, Zhongshan Hospital, Fudan University, Shanghai 200032; ${ }^{4}$ Department of Cardiovascular Diseases, Eastern District of Renji Hospital, Shanghai Jiaotong University, School of Medicine, Shanghai 200127, P.R. China
\end{abstract}

Received June 26, 2012; Accepted October 16, 2012

DOI: $10.3892 / \mathrm{mmr} .2012 .1159$

\begin{abstract}
The Janus kinase/signal transducer and activator of transcription pathway (JAK/STAT signaling pathway) is involved in the development of numerous cardiovascular diseases, although the specific role of this pathway in the pathogenesis of acute myocardial infarction (AMI) has not been elucidated. The purpose of this study was to evaluate the role of the JAK/STAT signaling pathway in the onset of AMI in rats. We also tested the effect of this pathway on nuclear factor $\kappa \mathrm{B}(\mathrm{NF}-\mathrm{\kappa B})$ expression in the myocardium and tumor necrosis factor- $\alpha$ (TNF- $\alpha$ ) levels in the plasma of AMI rats. An AMI rat model was successfully established and AG490 was used to block the JAK/STAT signaling pathway. The plasma TNF- $\alpha$ levels of AMI rats were measured by ELISA. The protein expression of NF- $\mathrm{kB}$ in the myocardial cells of AMI rats was detected by immunohistochemistry. The infarction area was significantly smaller in rats treated with AG490 after coronary artery ligation (group C) compared with that in the myocardial infarction control group (group B). The left ventricular mass indices in the sham surgery group (group A) and group $C$ were significantly lower compared with those of group B. Plasma TNF- $\alpha$ concentrations in group B were significantly higher compared with those of groups A and C. There were significantly fewer cardiomyocytes positively exhibiting $\mathrm{NF}-\kappa \mathrm{B}$ protein expression in groups $\mathrm{A}$ and $\mathrm{C}$ compared with group B. The JAK/STAT signaling pathway is involved in the
\end{abstract}

Correspondence to: Dr Yigang Li, Department of Cardiovascular Diseases, Xinhua Hospital, Shanghai Jiaotong University, School of Medicine, 1665 Kongjiang Road, Shanghai 200092, P.R. China E-mail: zhs16888@hotmail.com

Key words: Janus kinase/signal transducer and activator of transcription, signaling pathway, myocardial infarction, nuclear factor- $\kappa \mathrm{B}$, tumor necrosis factor- $\alpha$ onset of myocardial infarction and may also be involved in left ventricular remodeling after myocardial infarction. The involvement of the JAK/STAT signaling pathway in the onset of myocardial infarction may be correlated with its effects on the expression of NF- $\mathrm{kB}$ and TNF- $\alpha$.

\section{Introduction}

The Janus kinase/signal transducer and activator of transcription pathway (JAK/STAT signaling pathway) is an intracellular signaling pathway possessing interferon-like effects. The pathway is able to transduce the intracellular signals of various cytokines [tumor necrosis factor- $\alpha$ (TNF- $\alpha$ ), TGF- $\beta$ and IL] and thus regulate multiple physiological and pathophysiological processes, including immune responses, cell proliferation and differentiation, cell apoptosis, inflammation and cancer (1). The JAK/STAT pathway is also able to promote gene transcription following activation (2). This signaling pathway may be activated by several factors that include ischemia, hypoxia, inflammation and overactive renin-angiotensin processes. Despite its potential role in the ischemic pathology of cardiac muscle, the correlation between the JAK/STAT signaling pathway and the onset of acute myocardial infarction (AMI) has not been elucidated.

Nuclear factor $\kappa \mathrm{B}(\mathrm{NF}-\mathrm{\kappa B})$ is a nucleoprotein that is able to specifically bind to the 10-bp nucleotide sequence in the immunoglobulin $\kappa$ light chain gene and promote the expression of the $\kappa$ gene (3). Following activation, NF- $\mathrm{kB}$ quickly translocates into the nucleus from the cytoplasm and then binds to the specific $\kappa \mathrm{B}$ sites in the inducible gene promoter sequence. Then, various target gene expression may be induced, which may lead to cell and tissue damage and the development of various pathophysiological processes (4-8), including coronary heart disease and AMI.

In the present study, an AMI rat model was successfully established and AG490, a specific blocking agent, was used to inhibit the JAK/STAT signaling pathway. Plasma TNF- $\alpha$ levels in the AMI rats were measured by ELISA. NF- $\kappa B$ protein 
expression was detected in the myocardial cells of the AMI rats using immunohistochemistry. The role of the JAK/STAT signaling pathway in the onset of AMI, as well as its effect and significance on $\mathrm{NF}-\kappa \mathrm{B}$ expression in the myocardium and TNF- $\alpha$ levels in the plasma of AMI rats, were investigated.

\section{Materials and methods}

Animals. Wistar rats were obtained from the Laboratory Animal Center of Zhejiang University (Hangzhou, China). All rats were female and maintained under specific pathogen-free conditions. The experimental protocol was approved by the Animal Care and Use Committee of Zhejiang University and was performed in accordance with the Guide for the Care and Use of Laboratory Animals (NIH Publication No. 85-23, National Academy Press, WA, USA; revised 1996).

Main reagents. Pepsin, dimethyl sulfoxide (DMSO), TNF- $\alpha$ ELISA kit, normal goat serum, 3,3'-diaminobenzidine tetrahydrochloride (DAB), secondary antibody (rabbit anti-goat), streptavidin biotin-peroxidase complex (SABC), antigen restoration solution, occlusive solution and rabbit antidigoxin were purchased from Boster Biological Technology Ltd. (Wuhan, China), AG490 from Sigma Chemical Co. (St. Louis, MO, USA) and goat anti-rat primary antibody from Biocompare Co. (South San Francisco, CA, USA).

Establishment of the AMI animal models and specimen collection. The animals were anesthetized using an intraperitoneal injection of pentobarbital sodium $(40-60 \mathrm{mg} / \mathrm{kg})$. Following adequate anesthesia, the animals were intubated in a supine position and ventilated on room air via a small animal ventilator (HX100E, TME Co., China). A left thoracotomy was performed at the third intercostal space and the pericardium was opened. The left coronary artery was ligated permanently beneath the left atrial appendage with 6-0 sterile silk. The effectiveness of the ligation was confirmed when the color in the left ventricle below the ligation site changed from red to white. After the ligation was completed, the thorax was closed (9-11).

Female SD rats were used. A total of 30 rats were randomly selected for sham surgery and the rest underwent coronary artery ligation. Rats that survived the coronary artery ligation were randomly divided into a further 3 groups. Group A (sham surgery group, $n=30$ ) underwent the surgery without ligation. Plasma and heart samples were collected at 7, 14 and 28 days after surgery (groups A1, A2 and A3, respectively, with 10 animals in each subgroup). Group B (myocardial infarction control group, $n=30$ ) underwent ligation of the left anterior descending coronary artery. Plasma and heart samples were collected at 7, 14 and 28 days after surgery (groups B1, B2 and B3, respectively, with 10 animals in each subgroup). Group C (AG490 treatment + myocardial infarction group, $n=30$ ) also underwent coronary artery ligation. However, AG490 $(5 \mathrm{mg} / \mathrm{kg}$ / day) was administered by intraperitoneal injection at $96 \mathrm{~h}$ after ligation. The consecutive treatment lasted until the 27th day. The plasma and heart samples were collected at 7, 14 and 28 days after the surgery (groups C1, C2 and C3, respectively, with 10 animals in each subgroup). Group D (DMSO + myocardial infarction group, $n=30$ ) underwent coronary artery ligation and received $45 \%$ DMSO via intraperitoneal injection at $96 \mathrm{~h}$ after ligation. The consecutive treatment lasted until the 27 th day. The plasma and heart samples were collected at 7, 14 and 28 days after surgery (groups D1, D2 and D3, respectively, with 10 animals in each subgroup). Blood $(3 \mathrm{ml})$ was extracted by cardiac puncture and added to a tube with EDTA at the end of the experiment. The tube was gently agitated and the blood was centrifuged for $30 \mathrm{~min}$. It was then stored at $-20^{\circ} \mathrm{C}$. At the end of the experiment the chest was also opened and the heart was removed. The heart was fixed in $10 \%$ buffered formalin for $24 \mathrm{~h}$ and embedded in paraffin for immunohistochemical detection.

Measurement of infarct size. After the rat heart was harvested, the left ventricle was separated from the heart and weighed. It was sliced into 2-3-mm sections parallel to the atrioventricular groove. The sections were then incubated in $1 \%$ triphenyltetrazolium chloride (TTC) solution prepared in a $\mathrm{pH} 7.4$ phosphate buffer for $30 \mathrm{~min}$ at $37^{\circ} \mathrm{C}$. The slices were then incubated in the stain for $20 \mathrm{~min}$ at $37^{\circ} \mathrm{C}$ with constant agitation. In viable myocardium, TTC was converted by dehydrogenase enzymes to formazan, a red pigment that stained the tissue dark red. Non-viable infarcted myocardium that did not take up the TTC stain remained pale in color. The pale necrotic tissue was separated from the stained portions and weighed on an electronic balance. The weight ratio of the infarct size was calculated as the weight of the infarction zone divided by the weight of the heart $\mathrm{x} 100$.

ELISA test of plasma TNF- $\alpha$ (9). The coated antibody for TNF- $\alpha$ was added to the ELISA plate and stored at $4^{\circ} \mathrm{C}$ for $48 \mathrm{~h}$. The plate was then rinsed three times. The diluted sample solution and the standard solution were added and incubated at $37^{\circ} \mathrm{C}$ for $1 \mathrm{~h}$. The HRP-conjugated anti-TNF- $\alpha$ solution was added and incubated at $37^{\circ} \mathrm{C}$ for $1 \mathrm{~h}$. The plate was washed three times and the prepared ABTS [2,2'-azinobis(3-ethylbenzthiazoline-6-sulfonic acid)] chromogenic substrate reagent was added at $37^{\circ} \mathrm{C}$ for $25 \mathrm{~min}$. The optical density (OD) value was measured by a microplate reader set at $450 \mathrm{~nm}$.

Immunohistochemistry of $N F-\kappa B$ protein (9). The immunostaining procedure was performed on rat myocardium sections embedded in paraffin. The sections were deparaffinized in xylene and rapidly rehydrated using graded alcohols. Excess liquid was removed, and the sections were washed in phosphate-buffered solution (PBS; pH 7.4) with $0.05 \%$ Tween-20 (Sigma Chemical Co.). To reduce non-specific binding, normal goat serum (1\% in PBS) was applied to the slides for $30 \mathrm{~min}$ at $37^{\circ} \mathrm{C}$ and then incubated with monoclonal goat anti-rat primary antibody on consecutive sections. Following rinsing with PBS-T, the sections were incubated with specific secondary antibodies (rabbit anti-goat) for $1 \mathrm{~h}$ and then incubated with the biotinylated tyramide and streptavidin-peroxidase complexes. The immunoreaction was visualized using $0.015 \% \mathrm{H}_{2} \mathrm{O}_{2}$ in $\mathrm{DAB} / \mathrm{TBS}$ for $10 \mathrm{~min}$ at room temperature. In order to evaluate the extent of non-specific binding in the immunohistochemical experiments, control sections were incubated in the absence of the primary antibody.

The slides were examined under a microscope (Olympus, Tokyo, Japan) at x400 magnification. Eight areas per slide 
Table I. Percentage change in the myocardial infarct area (\%).

\begin{tabular}{lccc}
\hline Group & 7 days & 14 days & 28 days \\
\hline A & 0 & 0 & 0 \\
B & $23.65 \pm 5.33$ & $20.79 \pm 7.08$ & $21.46 \pm 5.81$ \\
C & $16.25 \pm 5.21^{\mathrm{a}}$ & $15.87 \pm 3.86^{\mathrm{a}}$ & $15.58 \pm 5.03^{\mathrm{a}}$ \\
D & $22.90 \pm 5.07^{\mathrm{b}}$ & $21.26 \pm 5.71^{\mathrm{b}}$ & $22.03 \pm 4.98^{\mathrm{b}}$ \\
\hline
\end{tabular}

${ }^{\mathrm{a} C}$ Compared with group $\mathrm{B}, \mathrm{P}<0.05$. ${ }^{\mathrm{b}}$ Compared with group $\mathrm{B}, \mathrm{P}>0.05$.

Table II. Left ventricular mass index of AMI rats.

\begin{tabular}{llll}
\hline Group & Weight $(\mathrm{g})$ & $\begin{array}{c}\text { Left ventricular } \\
\text { weight }(\mathrm{mg})\end{array}$ & LVMI $(\mathrm{mg} / \mathrm{g})$ \\
\hline A & $324.6 \pm 7.60$ & $718.2 \pm 37.08$ & $2.213 \pm 0.115$ \\
B & $303.4 \pm 9.32$ & $847.0 \pm 57.48$ & $2.795 \pm 0.214^{\mathrm{a}}$ \\
C & $310.8 \pm 8.84$ & $757.6 \pm 54.62$ & $2.473 \pm 0.198^{\mathrm{b}}$ \\
D & $303.0 \pm 13.91$ & $848.6 \pm 57.03$ & $2.806 \pm 0.227^{\mathrm{c}}$ \\
\hline
\end{tabular}

${ }^{\mathrm{a} C}$ Compared with group $\mathrm{A}, \mathrm{P}<0.05$. ${ }^{\mathrm{b}}$ Compared with group $\mathrm{B}, \mathrm{P}<0.05$. ${ }^{\circ}$ Compared with group $\mathrm{B}, \mathrm{P}>0.05$. AMI, acute myocardial infarction; LVMI, left ventricular mass index.

and six non-successive slides per sample were counted for the $\mathrm{NF}-\kappa \mathrm{B}$-positive stained cells. The number of positive cells was expressed as a percentage (\%) according to this formula: Percentage of NF- $\kappa \mathrm{B}$-positive stained cells $(\%)=$ number of $\mathrm{NF}-\kappa \mathrm{B}$-positive cardiomyocytes/total number of cardiomyocytes x 100 .

Detection of left ventricular mass index (LVMI). The body weight, left ventricular weight and heart weight in each group were measured at 28 days after surgery. The rats were sacrificed rapidly after their body weights were measured. The heart was removed quickly and placed into cold normal saline to clear the residual blood from the heart chamber. The heart was then dried with filter paper and weighed. The left ventricle was then separated along the auriculoventricular ring and the interventricular groove. The left ventricle was weighed and the LVMI was calculated. LVMI = left ventricular weight/body weight $(\mathrm{mg} / \mathrm{g})$.

Statistical analysis. Statistical analyses were performed to evaluate the differences between the experimental and control groups. The differences between groups were evaluated by using the one-way analysis of variance and the Student's t-test. $\mathrm{P}<0.05$ was considered to indicate a statistically significant difference.

\section{Results}

JAK/STAT signaling pathway and the change of myocardial infarct area. The infarction area in the AG490 treatment group (group C) was significantly less than that of the myocardial
Table III. Plasma TNF- $\alpha$ concentration in AMI rats (pg/ml).

\begin{tabular}{lccc}
\hline Group & 7 days & 14 days & 28 days \\
\hline A & $10.88 \pm 1.94$ & $7.48 \pm 1.41$ & $3.98 \pm 0.68$ \\
B & $42.91 \pm 3.62^{\mathrm{a}}$ & $27.93 \pm 2.21^{\mathrm{a}}$ & $25.71 \pm 1.64^{\mathrm{a}}$ \\
C & $21.50 \pm 1.39^{\mathrm{b}}$ & $12.91 \pm 1.65^{\mathrm{b}}$ & $11.43 \pm 1.16^{\mathrm{b}}$ \\
D & $43.48 \pm 2.36^{\mathrm{c}}$ & $28.03 \pm 1.63^{\mathrm{c}}$ & $25.56 \pm 1.19^{\mathrm{c}}$
\end{tabular}

${ }^{\mathrm{a}}$ Compared with group $\mathrm{A}, \mathrm{P}<0.05 .{ }^{\mathrm{b}}$ Compared with group $\mathrm{B}, \mathrm{P}<0.05$. ${ }^{\mathrm{c}}$ Compared with group $\mathrm{B}, \mathrm{P}>0.05$. TNF- $\alpha$, tumor necrosis factor- $\alpha$; AMI, acute myocardial infarction.



Figure 1. Left ventricular mass index of AMI rats (mg/g). AMI, acute myocardial infarction.

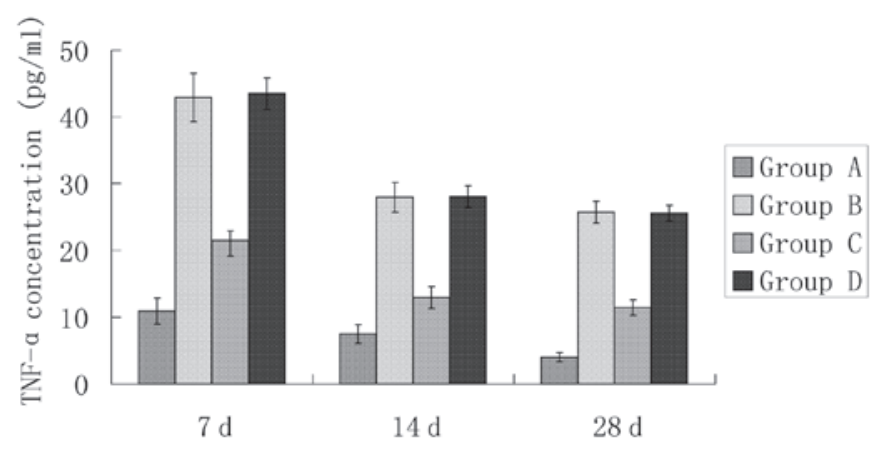

Figure 2. Comparison of TNF- $\alpha$ concentration in AMI rat (pg/ml). TNF- $\alpha$, tumor necrosis factor- $\alpha$; AMI, acute myocardial infarction.

infarction control group (group B; $\mathrm{P}<0.05$; Table I). There was no significant difference between the DMSO treatment group (group D) and group B.

Results of LVMI. The LVMIin the sham surgery group (group A) was significantly lower than that of group B $(\mathrm{P}<0.05$; Table II and Fig. 1). The LVMI in the AG490 treatment group (group C) was significantly lower than that of the myocardial infarction control group (group $\mathrm{B} ; \mathrm{P}<0.05$ ). There was no significant difference in the LVMI between the DMSO treatment group (group D) and group $\mathrm{B}(\mathrm{P}>0.05)$.

Plasma TNF- $\alpha$ in AMI rats. The TNF- $\alpha$ concentration was calculated according to the OD value of the sample. The TNF- $\alpha$ plasma concentration in the myocardial infarction control group (group B) was significantly greater than that 
Table IV. NF- $\kappa$ B protein expression in the AMI rats (\%).

\begin{tabular}{lccc}
\hline Group & 7 days & 14 days & 28 days \\
\hline A & $9.66 \pm 1.06$ & $3.82 \pm 0.91$ & $1.78 \pm 0.88$ \\
B & $73.33 \pm 10.74^{\mathrm{a}}$ & $43.96 \pm 7.70^{\mathrm{a}}$ & $37.08 \pm 7.90^{\mathrm{a}}$ \\
C & $38.41 \pm 5.12^{\mathrm{b}}$ & $24.42 \pm 5.12^{\mathrm{b}}$ & $19.73 \pm 4.80^{\mathrm{b}}$ \\
D & $74.03 \pm 10.06^{\mathrm{c}}$ & $42.13 \pm 5.12^{\mathrm{c}}$ & $35.07 \pm 5.28^{\mathrm{c}}$
\end{tabular}

${ }^{\mathrm{a} C}$ Compared with group $\mathrm{A}, \mathrm{P}<0.05 .{ }^{\mathrm{b}}$ Compared with group $\mathrm{B}, \mathrm{P}<0.05$. ${ }^{\mathrm{c}}$ Compared with group $\mathrm{B}, \mathrm{P}>0.05$. NF- $\mathrm{kB}$, nuclear factor $\kappa \mathrm{B}$; AMI, acute myocardial infarction.

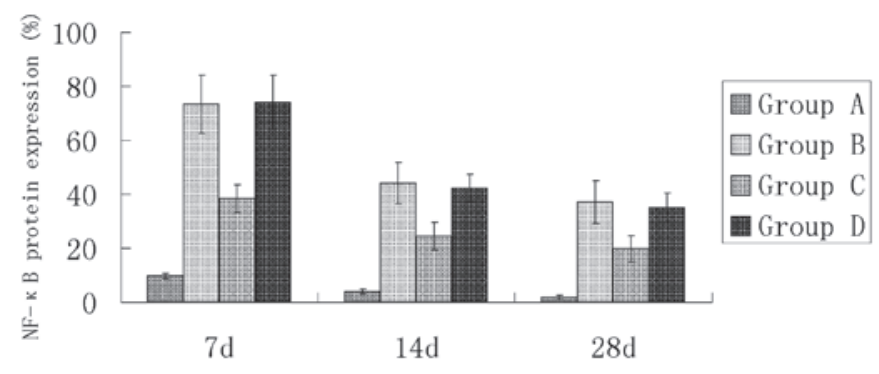

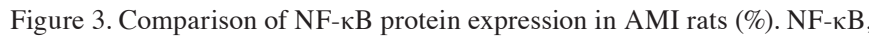
nuclear factor $\mathrm{\kappa B}$; AMI, acute myocardial infarction.

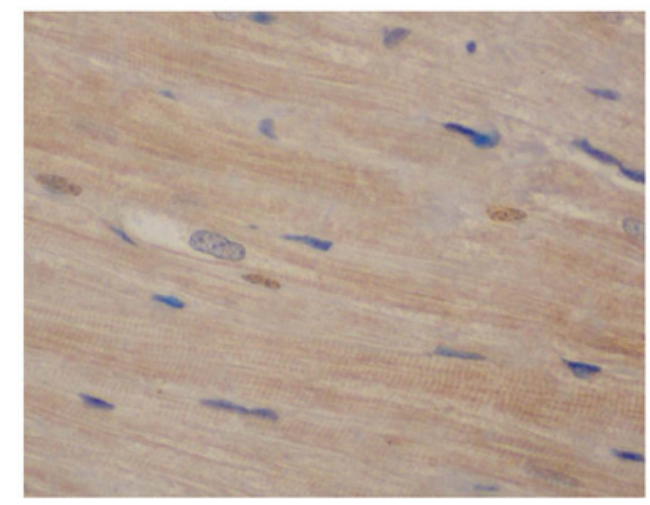

Figure 4. Sham surgery group showed a small amount of positive cardiomyocytes positive for NF- $\mathrm{BB}$ protein expression (magnification, $\mathrm{x} 400$ ). NF- $\mathrm{\kappa B}$, nuclear factor $\kappa \mathrm{B}$.

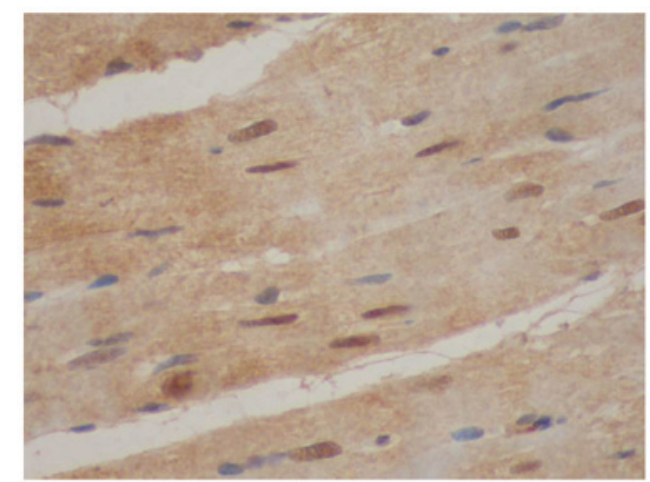

Figure 5 . NF-кB protein expression on day 7 following surgery in the myocardial infarction control group (SP staining, magnification, $\mathrm{x} 400$ ). NF- $\mathrm{\kappa B}$, nuclear factor $\mathrm{\kappa B}$.

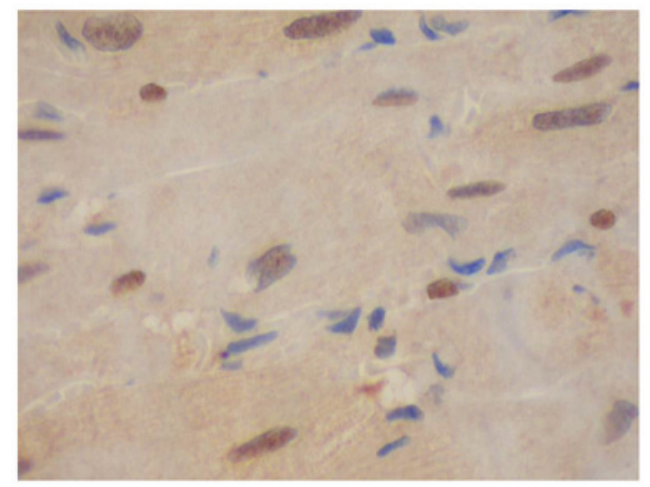

Figure 6. NF- $\mathrm{\kappa B}$ protein expression on day 7 following surgery in the AG490 treatment group (SP staining, magnification, $\mathrm{x} 400$ ). NF- $\kappa \mathrm{B}$, nuclear factor $\kappa \mathrm{B}$.

of the sham surgery group (group A; $\mathrm{P}<0.05$ ) and the AG490 treatment group (group C; $\mathrm{P}<0.05$; Table III and Fig. 2). No significant difference was detected in TNF- $\alpha$ between the DMSO treatment group (group D) and the myocardial infarction control group (group B).

Immunohistochemical detection of $N F-\kappa B$ protein expression. In the sham surgery group (group A), only a small number of cardiomyocytes positive for NF- $\mathrm{\kappa B}$ protein expression were observed (Table IV and Figs. 3 and 4). The number of cardiomyocytes positive for NF- $\mathrm{KB}$ protein expression was significantly greater in groups $\mathrm{B}, \mathrm{C}$ and $\mathrm{D}$ compared with group $A(P<0.05)$. There was no significant difference between groups $\mathrm{B}$ and $\mathrm{D}$, but the number of cardiomyocytes positive for $\mathrm{NF}-\kappa \mathrm{B}$ protein expression was significantly less in the AG490 treatment group (group C; Fig. 6) compared with the myocardial infarction control group (group B; Fig. 5; $\mathrm{P}<0.05$ ).

\section{Discussion}

A variety of cell signaling pathways play significant roles in the pathological changes that occur during and following myocardial infarction. These pathways may be activated by various factors that include inflammation and the overactive renin-angiotensin system. These pathways are able to protect the myocardium or cause further damage via downstream cytokines. The JAK/STAT signaling pathway plays a critical role in the signal transduction of cytokines, which are directly responsible for transferring the stimulation signals to the nucleus and promoting gene transcription. This pathway is widely involved in cell stress responses, apoptosis, inflammation and other biological processes, making it a key player in the occurrence and development of numerous cardiovascular diseases (12).

There are four kinase members in the JAK family, JAK1, JAK2, JAK3 and Tyk2. AG490 is a specific JAK tyrosine phosphorylation inhibitor, capable of effectively blocking the transduction of downstream signaling and inhibiting the activation of STAT (13). STAT is the downstream substrate of JAK and is a transcription factor in the cytoplasm that is able to bind to the specific DNA sequence of the regulatory region in the target gene. The JAK/STAT signaling pathway in the myocardium may be activated by various factors, including 
IL-6 (14), granulocyte colony stimulating factor, hypoxia and inflammation. Marked myocardial hypertrophy has been shown to develop in transgenic mice with STAT overexpression in the cardiac muscle. Thus, the overexpression of STAT and the activation of the JAK/STAT signaling pathway by the mechanical tension of the ventricular wall after myocardial infarction is a significant mechanism of myocardial hypertrophy following myocardial infarction.

Activation of the JAK/STAT signaling pathway and expression of the downstream substrate STAT is dependent on time passed since infarction, the region of myocardial infarction and the type of cells. Usually, ischemic pretreatment activates STAT1 and STAT3, ischemia-reperfusion activates STAT1, STAT5a and STAT6 and permanent myocardial ischemia activates STAT3 $(12,15,16)$. In addition, the JAK/STAT signaling pathway is closely correlated with myocardial hypertrophy after AMI and cardiac remodeling following myocardial infarction. The JAK/STAT signaling pathway is activated in AMI and has been revealed as playing a key role in cytoprotective signaling (15). In the present study, the infarct area was significantly reduced in the AG490 treatment group compared with that in the infarction control group; however, there was no significant difference in the DMSO treatment group. The infarct area likely decreased after blocking the JAK/STAT signaling pathway using AG490, suggesting that the JAK/STAT signaling pathway was correlated with the area of myocardial infarction and was involved in its onset.

LVMI is an important indicator used to evaluate left ventricular remodeling and left ventricular function. Our results revealed that the LVMI in the myocardial infarction group was significantly higher than that of the non-infarction groups. This finding may be attributed to left ventricular remodeling, left ventricular hypertrophy, growth promotion of catecholamine activated by infarction, proliferation via the renin-angiotensin system, proliferation and migration of the smooth muscle cells and collagen deposition caused by certain cytokines. These events contribute to the increased heart weight, which was particularly evident in the left ventricular region. The LVMI in the AG490 treatment group was significantly lower than in that the myocardial infarction control group, indicating that blocking the JAK/STAT signaling pathway inhibited cardiac hypertrophy and collagen matrix deposition, thereby inhibiting left ventricular remodeling. Collectively, these findings suggest that the JAK/STAT signaling pathway may be activated and involved in left ventricular remodeling after myocardial infarction.

$\mathrm{NF}-\kappa \mathrm{B}$ is a specific DNA binding protein that is found throughout eukaryotic cells and is responsible for multidirectional transcription regulation. A variety of stimulatory signals inside and outside cells activate $N F-\kappa B$ and stimulate the gene expression of a variety of active substances, including corresponding cytokines, adhesion molecules and immunerelated receptors. The nucleoprotein is involved in the growth and differentiation of cells, apoptosis, inflammation and tumorigenesis $(17,18) . \mathrm{NF}-\kappa \mathrm{B}$ was detected in the nuclear extracts of mature B lymphocytes for the first time by Sen and Baltimore (19) in 1986. It was revealed to specifically bind with the enhancer sequence in the immunoglobulin $\kappa$ light chain gene and promote its expression. It is known that there are more than 150 genes that may be regulated by NF- $\mathrm{BB}(20)$.
Previous studies (21-24) have shown that the NF- $\kappa \mathrm{B}$ activity in coronary atherosclerotic plaques increased, particularly in patients with unstable angina; the $\mathrm{NF}-\kappa \mathrm{B}$ activity in peripheral blood leukocytes in patients with unstable angina was higher than that in patients with stable angina. In addition, the NF- $\kappa \mathrm{B}$ activity in cardiomyocytes in the region of the myocardial infarction was higher than that in the areas that were absent of any infarction. In STAT1 mutant fibroblasts, STAT1 and $\mathrm{NF}-\kappa \mathrm{B}$ synergistically promoted pro-inflammatory cytokine transcription, indicating that the JAK/STAT signaling pathway promoted $\mathrm{NF}-\kappa \mathrm{B}$ activation and then induced or enhanced the inflammatory responses. $\mathrm{NF}-\kappa \mathrm{B}$ is closely associated with the occurrence and development of atherosclerosis, coronary heart disease, myocardial infarction, myocardial hypertrophy and congestive heart failure after myocardial infarction. In the present study, a greater number of cardiomyocytes positive for $\mathrm{NF}-\kappa \mathrm{B}$ protein expression were observed in the myocardial infarction control group compared with the non-infarction group. The number of positive cells was significantly reduced with the treatment of AG490, indicating that NF- $\kappa$ B expression was enhanced by AMI, and that blocking the JAK/STAT signaling pathway significantly reduced $N F-\kappa B$ expression. This finding suggests that a correlation exists between $\mathrm{NF}-\kappa \mathrm{B}$ expression and the activity of the JAK/STAT signaling pathway. Therefore, activation of the JAK/STAT signaling pathway may affect $\mathrm{NF}-\kappa \mathrm{B}$ expression and $\mathrm{NF}-\kappa \mathrm{B}$ may be involved in the occurrence and development of myocardial infarction.

In 1975, Carswell et al (25) found an active tumor necrosis factor that induced tumor cell necrosis, but caused no damage to the normal tissues and cells. Tumor necrosis factor may be divided into three subtypes: TNF- $\alpha,-\beta$ and $-\gamma$. TNF- $\alpha$ is mainly secreted by macrophages, although lymphocytes, monocytes, smooth muscle cells, fibroblasts and vascular endothelial cells are also able to produce and release TNF- $\alpha$ under certain conditions (25-30). It was identified that TNF- $\alpha$ levels increased in AMI and may be involved in the onset of myocardial infarction. Ridker et al (31) found that the risk of coronary event recurrence was greater in patients with higher plasma TNF- $\alpha$ levels after AMI. These authors also found that the frequency of recurrence of coronary events was positively correlated with the plasma TNF- $\alpha$ level. Animal experiments revealed that after ligation of the left anterior descending artery, TNF- $\alpha$ gene expression was promoted, which may be associated with vascular and ventricular remodeling after AMI (32). TNF- $\alpha$ is able to induce extracellular matrix changes, collagen matrix remodeling and promote the hypertrophy of cardiomyocytes by the destruction of collagen and an increase in the amount of denatured collagen fibers in myocardium. TNF- $\alpha$ is also able to promote myocardial cell apoptosis, which may result in fewer myocardial cells and more fibrous tissues. Our results showed that the plasma TNF- $\alpha$ concentration was increased in the AMI group and was significantly decreased following the inhibition of the JAK/STAT signaling pathway by AG490. The results indicated that the TNF- $\alpha$ level was correlated with and dependent on the JAK/STAT signaling pathway. This finding may be attributed to the binding sites of STAT in the mRNA promoter of TNF- $\alpha$. The inhibition of STAT activity by AG490 may reduce TNF- $\alpha$ mRNA transcription (33). Several studies have shown that following myocardial infarction, $\mathrm{TNF}-\alpha$ concentration in the infarction area was increased. 
However, increases in TNF- $\alpha$ concentration were also noted in the normal myocardium of non-infarct areas. Thus, AG490 may inhibit the inflammatory responses after myocardial infarction, improve the cardiac hypertrophy, reduce fibrosis and attenuate the renin-angiotensin system response. This may ultimately reduce myocardial remodeling following AMI. These findings suggest that the JAK/STAT signaling pathway is able to affect TNF- $\alpha$ concentration and that the latter may be involved in the development of myocardial infarction.

\section{References}

1. Igaz P, Toth S and Falus A: Biological and clinical significance of the JAK-STAT pathway; lessons from knockout mice. Inflamm Res 50: 435-441, 2001.

2. Kisseleva T, Bhattacharya S, Braunstein $\mathrm{J}$ and Schindler CW: Signaling through the JAK/STAT pathway, recent advances and future challenges. Gene 285: 1-24, 2002.

3. Sen R and Baltimore D: Multiple nuclear factors interact with the immunoglobulin enhancer sequences. Cell 46: 705-716, 1986

4. Yeh CH, Chen TP, Wu YC, Lin YM and Jing Lin P: Inhibition of NFkappaB activation with curcumin attenuates plasma inflammatory cytokines surge and cardiomyocytic apoptosis following cardiac ischemia/reperfusion. J Surg Res 125: 109-116, 2005.

5. Altavilla D, Deodato B, Campo GM, et al: IRFI 042, a novel dual vitamin E-like antioxidant, inhibits activation of nuclear factorkappaB and reduces the inflammatory response in myocardia ischemia-reperfusion injury. Cardiovasc Res 47: 515-528, 2000.

6. Christman JW, Lancaster LH and Blackwell TS: Nuclear factor kappa B: a pivotal role in the systemic inflammatory response syndrome and new target for therapy. Intensive Care Med 24 1131-1138, 1998.

7. Chen J, Jiang H, Yang J, Chen SS and Xu L: Down-regulation of CREB-binding protein expression blocks thrombin-mediated endothelial activation by inhibiting acetylation of NF-kappaB. Int J Cardiol 154: 147-152, 2012.

8. Fan Y, Wang J, Wei L, He B, Wang C and Wang B: Iron deficiency activates pro-inflammatory signaling in macrophages and foam cells via the p38 MAPK-NF-kappaB pathway. Int J Cardiol 152: 49-55, 2011.

9. Zhang S, He B, Goldstein S, Ge J, Wang Z and Ruiz G: Changes in adiponectin expression in acute myocardial infarction rats and the significance of bisoprolol intervention. Can J Physiol Pharmacol 89: 109-115, 2011.

10. Zhang S, He B, Ge J, Zhai C, Liu X and Liu P: Characterization of chemical composition of Agaricus brasiliensis polysaccharides and its effect on myocardial SOD activity, MDA and caspase-3 level in ischemia-reperfusion rats. Int J Biol Macromol 46: 363-366, 2010.

11. Zhang S, He B, Ge J, et al: Extraction, chemical analysis of Angelica sinensis polysaccharides and antioxidant activity of the polysaccharides in ischemia-reperfusion rats. Int J Biol Macromol 47: 546-550, 2010

12. Booz GW, Day JN and Baker KM: Interplay between the cardiac renin angiotensin system and JAK-STAT signaling: role in cardiac hypertrophy, ischemia/reperfusion dysfunction, and heart failure. J Mol Cell Cardiol 34: 1443-1453, 2002.

13. Strutz F and Muller GA: The role of tubulo-interstitial processes in progression of primary renal diseases. Nephr Dial Transplant 9: 10-20, 1994.

14. Boengler K, Hilfiker-Kleiner D, Drexler H, Heusch G and Schulz R: The myocardial JAK/STAT pathway: from protection to failure. Pharmacol Ther 120: 172-185, 2008.

15. Negoro S, Kunisada K, Tone E, et al: Activation of JAK/STAT pathway transduces cytoprotective signal in rat acute myocardial infarction. Cardiovasc Res 47: 797-805, 2000.
16. Mascareno E, El-Shafei M, Maulik N, et al: JAK/STAT signaling is associated with cardiac dysfunction during ischemia and reperfusion. Circulation 104: 325-329, 2001.

17. Heyninck K, Kreike MM and Beyaert R: Structure-function analysis of the A20-binding inhibitor of NF-kappa B activation, ABIN-1. FEBS Lett 536: 135-140, 2003.

18. Nair A, Venkatraman M, Maliekal TT, Nair B and Karunagaran D: NF-kappaB is constitutively activated in high-grade squamous intraepithelial lesions and squamous cell carcinomas of the human uterine cervix. Oncogene 22: 50-58, 2003.

19. Sen R and Baltimore D: Inducibility of kappa immunoglobulin enhancer-binding protein Nf-kappa B by a posttranslational mechanism. Cell 47: 921-928, 1986.

20. Pahl HL: Activators and target genes of Rel/NF-kappaB transcription factors. Oncogene 18: 6853-6866, 1999.

21. Rodriguez-Porcel M, Lerman LO, Holmes DR Jr, Richardson D, Napoli C and Lerman A: Chronic antioxidant supplementation attenuates nuclear factor-kappa B activation and preserves endothelial function in hypercholesterolemic pigs. Cardiovasc Res 53: 1010-1018, 2002

22. Dichtl W, Nilsson L, Goncalves I, et al: Very low-density lipoprotein activates nuclear factor-kappaB in endothelial cells. Circ Res 84: 1085-1094, 1999.

23. Ritchie ME: Nuclear factor-kappaB is selectively and markedly activated in humans with unstable angina pectoris. Circulation 98: 1707-1713, 1998

24. Kawano S, Kubota T, Monden Y, et al: Blockade of NF-kappaB improves cardiac function and survival after myocardial infarction. Am J Physiol Heart Circ Physiol 291: H1337-H1344, 2006.

25. Carswell EA, Old LJ, Kassel RL, Green S, Fiore N and Williamson B: An endotoxin-induced serum factor that causes necrosis of tumors. Proc Natl Acad Sci U S A 72: 3666-3670, 1975.

26. Shaw T, Nixon JS and Bottomley KM: Metalloproteinase inhibitors: new opportunities for the treatment of rheumatoid arthritis and osteoarthritis. Expert Opin Investig Drugs 9: 1469-1478, 2000.

27. Huang NL, Chiang SH, Hsueh $\mathrm{CH}$, Liang YJ, Chen YJ and Lai LP: Metformin inhibits TNF-alpha-induced IkappaB kinase phosphorylation, IkappaB-alpha degradation and IL-6 production in endothelial cells through PI3K-dependent AMPK phosphorylation. Int J Cardiol 134: 169-175, 2009.

28. Cao YL, Wang YX, Wang DF, Meng X and Zhang J: Correlation between omental TNF-alpha protein and plasma PAI-1 in obesity subjects. Int J Cardiol 128: 399-405, 2008.

29. Conraads VM, Denollet J, De Clerck LS, Stevens WJ, Bridts C and Vrints CJ: Type D personality is associated with increased levels of tumour necrosis factor (TNF)-alpha and TNF-alpha receptors in chronic heart failure. Int J Cardiol 113: 34-38, 2006.

30. Sharma R and Anker SD: Cytokines, apoptosis and cachexia: the potential for TNF antagonism. Int J Cardiol 85: 161-171, 2002.

31. Ridker PM, Rifai N, Pfeffer M, Sacks F, Lepage S and Braunwald E: Elevation of tumor necrosis factor-alpha and increased risk of recurrent coronary events after myocardial infarction. Circulation 101: 2149-2153, 2000.

32. Irwin MW, Mak S, Mann DL, et al: Tissue expression and immunolocalization of tumor necrosis factor-alpha in postinfarction dysfunctional myocardium. Circulation 99: 1492-1498, 1999.

33. Held TK, Weihua X, Yuan L, Kalvakolanu DV and Cross AS: Gamma interferon augments macrophage activation by lipopolysaccharide by two distinct mechanisms, at the signal transduction level and via an autocrine mechanism involving tumor necrosis factor alpha and interleukin-1. Infect Immun 67: 206-212, 1999 